\title{
The Pupils' Academy of Serious Gaming: Strengthening Study Skills
}

\author{
http://dx.doi.org/10.3991/ijep.v5i3.4660 \\ Matthias Christoph Utesch \\ Lehrstuhl für Wirtschaftsinformatik, Technische Universität München \\ Staatliche Fachober- und Berufsoberschule Technik München
}

\begin{abstract}
The Pupils' Academy of Serious Gaming at the 'Technische Universität München' TUM is a reliable instrument to successfully strengthen the study skills of students from the upper vocational schools of Bavaria. Based on the pedagogy of a practical application of sciences, we enable the participants to change their learning perspective from 'school student' to 'university student': For two days they take part in a regular course at TUM based on our inhouse business game Go4C. The goal is to learn how to selfassess and develop important aspects of their personal study skills. This paper presents the Pupils' Academy and Go4C as a tool to strengthen the study skills at an early stage before leaving school.
\end{abstract}

Index Terms-business game, didactic framework, strengthen study skills, vocational schools.

\section{INTRODUCTION}

In this paper we present the Pupils' Academy of Serious Gaming at the 'Technische Universität München' TUM, which, for more than five years, has been a reliable instrument to successfully strengthen the study skills of students from the upper vocational schools of Bavaria. It focuses on application-oriented learning with our business game Go4C [1].

Following this first chapter on the structure of this paper, the second chapter will give an overview of the contents and educational objectives of the Pupils' Academy. We will introduce our target group: the students of the upper vocational schools.

In the third chapter we will discuss those two main aspects of the study skills which are most significant to the students of the upper vocational schools of Bavaria.

The fourth chapter will explain the five phases of interaction for application-oriented learning with the business game Go4C. Then the fifth chapter will describe the Didactic Framework of Go4C and how it reflects the study skills.

In the sixth chapter we will discuss the results of the Pupils' Academy by means of a survey. The seventh chapter finally will draw a conclusion of our approach.

\section{The PuPILs' ACADEMY OF SERIOUS GAMING}

The Pupils' Academy of Serious Gaming is a joint project of the Department of Informatics at the 'Technische Universität München' TUM and the 'FOS/ BOS Munich for Technology' on behalf of the upper vocational schools of Bavaria/Germany.

The upper vocational schools 'Berufsoberschule' (BOS) and 'Fachoberschule' (FOS) provide a university access, which focuses on a practical approach. In the school year 2013/14 a total of 63,722 students graduated at all types of upper secondary schools in Bavaria. 26,032 graduates - or $41 \%$ - came from vocational schools [2].

The Pupils' Academy takes place every year in the week from the end of June to the beginning of July. The participants are $11^{\text {th }}$ graders of upper vocational schools. They have nearly mastered the first year of a two-yearcourse. At the end of the $12^{\text {th }}$ grade they will sit the final examination (the German 'Abitur'), which will grant access to university studies.

At the end of grade 11, we want the students of the upper vocational school to start seeing themselves as future university students. So the intention of the Pupils' Academy is to strengthen their study skills in order to support the transition from upper vocational school to university. This means:

- To raise their awareness of the study skills

- To inform them at full length about the various aspects of the study skills

- To offer the personal experience of strengthening one's own study skills

As a particularly suitable tool we use the business game Go4C [1]. Nowadays, serious games and especially business games are well established as part of learning scenarios not only for students at schools and universities but for top-level managers, too.

With Go4C the students take their chances as top-level managers of the 'TechniCar Autobank'. By this means Go4C imparts, in an integrated, application-oriented manner, both business administration skills and two main aspects of the study skills: methods of science and a clear idea of the studies at university.

The successful participants of the Pupils' Academy are awarded a certificate issued by the TUM in cooperation with the 'Bayerisches Staatsministerium für Bildung und Kultus, Wissenschaft und Kunst', the Bavarian State Ministry of Education and Teaching, Science and Art. Combined with the German 'Abitur', this certificate may help the students to successfully manage the transition towards university.

\section{Two MAIN AsPeCts OF THE STUDY SKILLS}

The Bavarian upper vocational schools offer their students a couple of measures facilitating the transition from school to university. These measures almost exclusively consist of presentations by universities like academic information events or Open Days. Unfortunately, at these 
presentations the participants only passively receive information.

But what would it be like, if the students themselves became actively involved? What would it be like, if the students of BOS and FOS could not only acquire technical knowledge in their regular lessons, but also study skills?

Five years ago, in response to these questions, we developed the 'Pupils' Academy of Serious Gaming'. The approach is to actively involve the students via application-oriented scenarios. Thus we strengthen their study skills in a way that best supports their learning behavior.

The Pupils' Academy focuses on a change of perspective: for two days the students of upper vocational schools take on the role of a university student. They experience university first hand, but playfully. Thus, they strengthen their own study skills - one year before university actually starts.

Which of the various aspects of the study skills are particularly important for the specific requirements of application-oriented learning among BOS and FOS students?

The BuS program - 'Beruf und Studium' (work and study ) - of the State Institute for School Quality and Educational Research, ISB Munich, provides the answer to this question for schools in Bavaria. BuS is a voluntary and systematic program to support the decision-making process on career or degree [3].

At each upper vocational school, educational and career guidance counsellors assist students and their parents in dealing with the many issues of the transition from school to university. We benefitted from this expert knowledge. Based on the BuS and hand in hand with the counsellors we developed a catalogue containing those aspects of the study skills which meet the requirements of upper vocational schools. Finally, this catalogue was cross-checked by the experts responsible for upper vocational schools at the Bavarian State Ministry of Education and Teaching, Science and Art.

In this way, our two main aspects of the study skills and their related sub-aspects were established.

\section{A. Methods of science}

Successful students master a wide range of methods of science. They should be able to:

1. handle complex issues without hesitation

2. mindfully choose the most appropriate approach out of several options

3. focus on learning for a sufficient period of time without being distracted

4. optimize their time management according to their own biological rhythm (optimal time to work)

5. work well under pressure.

\section{B. A clear idea of the studies at university}

With this aspect we draw the attention of the students of BOS and FOS to the organizational questions of taking up a degree course. As early as possible, every student should:

1. mindfully choose a suitable field of study
2. grow familiar with the application process of their favorite university.

So far, the students of upper vocational schools feel safe with lessons that follow a fixed timetable, which is predetermined by their school. Now, they should develop a clear idea on:

3. the daily routine at university

4. how a typical lecture at university works.

\section{THE FIVE INTERACTION PHASES OF GO4C}

Go4C is a turn-based business game which was developed in-house at TUM. The scope of Go4C is to practice the application of state-of-the-art information technology to successful management processes within the simulated environment of a company [1]. Go4C has been applied to the Master's in Information Systems and Economics course at TUM since 2001 and the Pupils' Academy of Serious Gaming since 2009.

Have you ever experienced a business game as part of a learning scenario? The learning with business games not only improves technical knowledge. According to research which is described in scientific literature, for example by [4], we experienced Go4C as best suited to acquire not just technical competences but also metacognitive competences such as time management, communication and presentation skills and problem solving strategies. The unique strength of Go4C is its application-oriented learning approach. Therefore, in 2009, Go4C seemed to be the best tool for the students at BOS and FOS to strengthen study skills according to the aspects presented in chapter III.

The subject-related goals of Go4C have their roots in the science of applied business information management. A company must be consolidated and its profits and growth should be sustainably developed. From a didactical point of view, Go4C follows a constructivist approach to learning in the tradition of [5]. As described by [6], Go4C promotes self-regulated learning according to [7] and personalized learning summarized in [8].

The company itself is a virtual bank, called 'TechniCar' whose product portfolio focuses on car financing and savings accounts. The savings will be used to finance the loans for cars. The interest rate of the car financing business should be significantly higher than the one related to the savings accounts: the larger the gap between the two rates, the higher is the profit. In addition, TechniCar generates profits through transactions on the interbank market.

The user interface of Go4C is a state-of-the-art management information system (MIS). Through MIS the learners control TechniCar. They carry out business analyses, develop strategies, implement them and evaluate their impact. MIS comprises several hundreds of economic indicators, which are organized through a balance sheet, a profit and loss statement, and a Balanced Scorecard as proposed by [9] including data on market / competition and the staff.

The administration interface of Go4C enables the game tutors to visualize and compare all indicators over time. We use this feature to evaluate the achievements of the learners at the end of each turn and give them valuable feedback. Thus the learners will enhance their technical 
and metacognitive abilities with every decision made in the "played reality" of TechniCar as observed by [10].

Each student of upper vocational schools plays one out of four roles as top manager of TechniCar: Chief Financial Officer (CFO), Chief Information Officer (CIO), Chief Marketing Officer (CMO) or Chief Operating Officer (COO). Thus you need four students forming a group to share control of the company as a management team including any kind of $\mathrm{CxO}$. A Pupils' Academy supports a maximum of four courses, each encompassing up to six management teams.

Each management team competes turn-based and independently of the other teams against a computer scenario. The duration of a turn is determined by the tutors in coordination with the learners. Every turn simulates one half of a fiscal year.

At the start of the business game the (car financing interest) revenues are no longer sufficient in order to cover the (customer savings interest) cost and other expenses. The net income of the last fiscal year is worryingly a negative.

The process flow of the business game Go4C covers five Interaction Phases (see Fig. 1). These five phases represent in more detail the traditional phased model for teaching and learning as presented by [11] consisting of analyzing, problem solving and feedback/transfer.

1. Analyze the problem: In the first turn of a simulation each management team must strive to understand the current business situation and decide on a business objective for TechniCar, e.g. achieve the highest net income compared to the other teams.

Starting with the second turn it is important to analyze the degree to which TechniCar has met its business objective. What have the results of the last simulation turn been? Which changes in the indicators does the MIS show?

2. Develop a business strategy: Following a careful analysis of the problem, you have to develop a strategy for achieving the business objective. This strategy must be described in form of MIS indicators. Ideally, this description includes a sub-target and its related business processes for each of the following turns. According to our experience, the learners create a strategy by first phrasing some hypotheses on the current business situation of TechniCar. Then the learners create a spreadsheet in order to anticipate the next turn.

3. Implement the business strategy: On the basis of the strategy and according to their respective area of responsibility within the top management each $\mathrm{CxO}$ implements the appropriate input values to run the company. It is very important that the $\mathrm{CxOs}$ act as a team and coordinate their inputs. Especially the CFO should ensure that sufficient financial resources are available to finance the operational business transactions of his colleagues.

4. Run the simulation: When the agreed time has elapsed for the current turn, the user interface is locked. Then the game administrator runs the computer simulation of the current half of a business year. The simulation normally takes about ten minutes.
5. Present the results: Each team receives the results of the computer simulation of their business activities. The participants have to present a target/ actualcomparison on the business situation of their company based on the MIS indicators. This is staged like an executive presentation given by a real management board to the supervisory board. The latter is played by the tutors of the Pupils' Academy.

Target: Which business objective was targeted? Which business strategy was implemented? Which transactions were carried out?

Actual: What has actually been achieved? Which deviation from the company's target performance exists and what is its underlying course? What sub-targets will you envisage during the next turns?

After the executive presentation the next turn starts with the first Interaction Phase again. It is mainly due to this iteration of the Interaction Phases that the students of upper vocational schools enhance their study skills. This principle follows the Plan-Do-Check-Act Cycle of W. Deming. Our approach to the PDCA Cycle will be illustrated in the fifth chapter of this paper by the Didactic Framework of Go4C.

\section{THE DidACTIC FrameWORK OF GO4C}

Our many years of experience with Go4C and other game-based teaching and learning scenarios have been documented in the Didactic Framework of Go4C (Fig. 1). According to the findings of [12] and [13], this framework equals a process flow which is structured in the four stages Preparation, Introduction, iteration of Interaction Phases (see Chapter IV) and Conclusion.

The Pupils' Academy mainly consists of up to seven iterations of the Interaction Phases. Each of the iterations equals a single turn in the turn-based course of the business game Go4C. During the turns, the participants strengthen their study skills according to the aspects described in the third chapter. With each single turn, the participants master the game controls of Go4C more and more confidently and understand the business processes of TechniCar better and better.

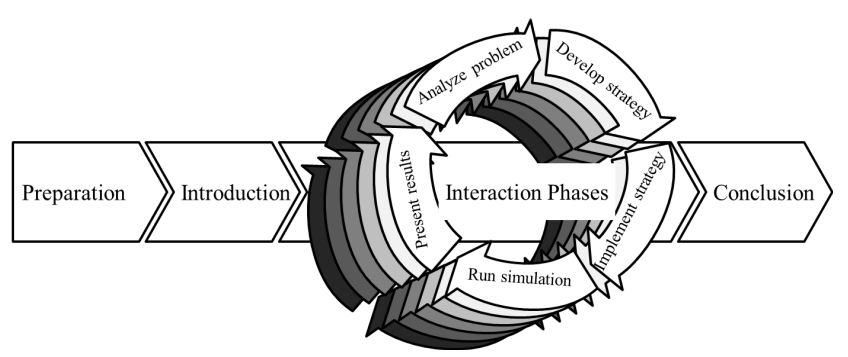

Figure 1. Interaction Phases and Didactic Framework

Following the concept of error management training described by [14], it is important that the participants learn to both recognize and deal with inexpedient strategies, unexpected difficulties or mistakes. Then they may do better during the next turn and their success will be celebrated. 
On the one hand, this allows us to increase the difficulty of the tasks to be solved in Go4C with each turn. On the other hand, instead of us teaching technical competences only, we may guide the participants to autonomous learning as proposed by Aviram [15]. Johannes Wildt propagates this "Shift from Teaching to Learning" [16] as the most important didactical approach towards outstanding study skills.

So far we gave a short overview of the didactic framework of Go4C. The individual stages will be explained below.

\section{A. Preparation}

The first stage called Preparation is for establishing the organizational conditions needed to conduct the Pupils' Academy successfully. It is very important to brief participants on the objectives of the course. As described in the fourth chapter, the Pupils' Academy supports a maximum of four courses, each encompassing up to six management teams, i.e. a maximum of 96 students of the upper vocational school altogether. Each course stays at TUM for two days.

There are some legal aspects we have to consider during Preparation. In strictly legal terms each participant of the Pupils' Academy has the status of a student of upper vocational school not that of a university student. Therefore the school sending a participant must clearly take the disciplinary responsibility and be accountable for all aspects related to insurance-law.

Which competences do the participants need in preparation for the Pupils' Academy?

They should already have some basic experiences in teamwork, presentations in front of class and in handling technical texts. They need to master the calculation of interest rates. The best way to learn this would be during the lessons on spreadsheet analysis, which are mandatory in the curriculum for the $11^{\text {th }}$ grade of the upper vocational school.

\section{B. Introduction}

What are the business challenges that the TechniCar bank has to deal with every day? Which business processes and respective roles does $\mathrm{Go} 4 \mathrm{C}$ offer for managing TechniCar? Answering these two questions is the task of our participants in the second stage named Introduction. The manual and the related FAQs provide the relevant information [1].

The students become acquainted with the roles of the management board and collect their first experiences with the various aspects of the study skills as follows: We use a cooperative learning technique according to the Jigsaw Classroom of [17].

First, four specific expert groups are formed: CFO, $\mathrm{CIO}, \mathrm{CMO}$ and COO. Their respective assignment is to explore their area of responsibility, the operating interface and the business process from the point of view of their management role. The acquired knowledge is to be documented on flip charts. After 45 minutes, the expert groups have to present their results to all participants. We display the flipcharts in the course room to serve as memory aids during the Pupils' Academy.
Second, having finished their presentations, the expert groups dissolve and the participants reassemble in the management board meetings of TechniCar in preparation of the Interaction Phases. Thus, each management board consists of four participants in the roles of $\mathrm{CFO}$, CIO, $\mathrm{CMO}$ and COO. This way, we transfer the expertise on the $\mathrm{CxO}$ roles to each management board. It should be kept in mind that the Pupils' Academy supports a maximum of up to six management teams in a course.

The tutors of the Pupils' Academy play the role of the supervisory board of TechniCar. Thus, they are truly integrated in the business game from the very beginning of the stage Introduction. The tutors are not only able to help the participants with purely technical knowledge, they also provide methodological support from the inside of the "Played Reality". According to their feedback, the participants very much appreciate this collaboration with tutors at "eye level".

\section{First Turn of Go4C}

Go4C is the simulation of a (real-world) car financing bank, a business game. We strive to create an authentic atmosphere as well as possible. The participants should experience TechniCar and their membership in its management board as a thrilling "Played Reality". They should personally identify with the TechniCar bank and its exciting business.

The crucial factor for this change of perspective is the right attunement of the participants to the business situation at the start of the first turn - the first iteration of the Interaction Phase. For this our scenario 'Paper Snippets' [1] has proved to be very useful. Thereby one of us slips into the role of the chairman of the supervisory board of TechniCar and addresses his future top managers:

\section{"Ladies and Gentlemen,}

Our initial situation is as follows: The car financing revenues are no longer sufficient to cover our expenses. We suspect that the cause for this trouble is that too large a proportion of the liabilities of TechniCar consists of expensive loans from the Central Bank.

Unfortunately our former top management has always rejected suggestions from employees. Expressing his outrage at this ignorance, our most promising junior banker has switched to a competitor. In his wastepaper basket we found paper snippets, which probably outline a very promising financing solution. Needless to say, we secured these paper snippets.

Your first task is to use them to reconstruct a sound financing solution for our liabilities - a solution without Central Bank loans.

You will form the NEW management board of TechniCar. You will consolidate TechniCar! You will ensure its profits and growth!"

Figure 2 lists those fourteen paper snippets, which have to be taken into account in order to reconstruct a sound financial solution without central bank loans. More optional snippets may be added in order to increase the difficulty of the scenario. In principle, the paper snippets summarize information from the balance sheet, profit and loss statement and the Balanced Scorecard of Go4C. 


\begin{tabular}{|c|c|}
\hline 1 & Central Bank loans cost 18 percent per year. \\
\hline 2 & TechniCar has \$ 676.19 million Central Bank loans. \\
\hline 3 & $\begin{array}{l}\text { The balance sheet of TechniCar contains assets in the form of } \\
\text { T-Bills worth } \$ 227.50 \text { million. }\end{array}$ \\
\hline 4 & $\begin{array}{l}\text { The interest rates for T-Bills and T-Bonds are set at four } \\
\text { percent per year. }\end{array}$ \\
\hline 5 & $\begin{array}{l}\text { T-Bonds worth } \$ 227.5 \text { million are shown in the balance sheet } \\
\text { as assets of TechniCar. }\end{array}$ \\
\hline 6 & $\begin{array}{l}\text { From TechniCar's point of view it is clear that Repos are } \\
\text { liabilities, Reverse Repos are assets. }\end{array}$ \\
\hline 7 & $\begin{array}{l}\text { The interest rates for Repos and Reverse Repos amount to five } \\
\text { percent per year. }\end{array}$ \\
\hline 8 & TechniCar owns $\$ 250.00$ million Reverse Repos. \\
\hline 9 & TechniCar is financed by $\$ 530$ million Repos. \\
\hline 10 & $\begin{array}{l}\text { The interest revenues of TechniCar do not cover the interest } \\
\text { expenses. }\end{array}$ \\
\hline 11 & $\begin{array}{l}\text { TechniCar must pay } 11 \text { percent interest for Bank Loans } \\
\text { Liabilities per year. }\end{array}$ \\
\hline 12 & $\begin{array}{l}\text { The interest rate for Bank Loans Assets is set at six percent } \\
\text { per year. }\end{array}$ \\
\hline 13 & TechniCar owns \$ 360.00 million Bank Loan Assets. \\
\hline 14 & $\begin{array}{l}\text { The Bank Loan Liabilities of TechniCar amount to } \$ 403.00 \\
\text { million. }\end{array}$ \\
\hline
\end{tabular}

Figure 2. Fourteen paper snippets

\section{Iteration of the Interaction Phases}

The scenario 'Paper Snippets' covers the first iteration of the Interaction Phases. The Pupils' Academy as a whole is built on the principle of the 'flow-theory'. With each iteration of the Interaction Phases, the participants are confronted with an even more challenging task [18]. The more they become involved with the "Played Reality" of TechniCar and the more they identify with their role in the management board, the more they will be taken away by the "flow" and the more they will enjoy strengthening their study skills! The more the participants enjoy Go4C as a game and not as a medium for learning [19], the higher their intrinsic motivation to learn will be.

The cognitive processes triggered by each iteration are described according to the taxonomy of educational objectives developed by [20]. We use a German nomenclature (see Table I) according to [21].

\section{TABLE I. NOMENCLATURE}

\begin{tabular}{|l|l|l|}
\hline Understand & Verstehen & $\square$ \\
\hline Apply & Anwenden & $\square$ \\
\hline Analyze & Analysieren & $\mathbf{\square}$ \\
\hline Evaluate & Auswerten & $\mathbf{\square}$ \\
\hline Create & Erschaffen & $\mathbf{\square}$ \\
\hline
\end{tabular}

Each process is visualized by a symbol. The cognitive process "Understand $\square$ " at the beginning of an iteration means that we give a lecture on the respective theory, e.g. we explain the user interface of the MIS at the beginning of the first iteration.

On the basis of this nomenclature all iterations and their associated knowledge dimensions are listed in Table II.

Each knowledge dimension is related to a couple of new tasks that the participants have to include in the operational business activities of TechniCar by realigning the business objective and the respective strategy after each of the iterations.

The first iteration is mainly intended to grow familiar with the user interface of Go4C. Where to find what? Which indicators does the MIS contain and how can I change their values? How do you implement an operative decision and evaluate its impact? According to our experi- ence with Go4C, particularly the first presentation of results serves for clarifying those questions. For further assistance we always recommend to look up the FAQs documented in [1].

During the first two iterations, the process flow of the five Interaction Phases is established. Here the assistance of the tutors is more important than during the following iterations.

The teams establish their modus operandi and practice communication and cooperation in their respective $\mathbf{C x O}$ roles of the management boards: $\mathrm{CFO}, \mathrm{CIO}, \mathrm{CMO}$ and COO. They learn to present results in a concise and businesslike manner.

According to the scenario 'Paper Snippets', the first two iterations focus on the consolidation of the liabilities by replacing the central bank credit with an alternative financing solution based on a much lower interest rate. The participants learn how to apply the mathematical basics of the calculation of interest rates to the situation of TechniCar: Is it possible to finance TechniCar without any central bank loans?

TABLE II. ITERATIONS AND ASSOCIATED KNOWLEDGE DIMENSIONS

\begin{tabular}{|l|l|l|l|l|l|l|l|}
\hline \multicolumn{1}{|r|}{ Iteration } & 1 & 2 & 3 & 4 & 5 & 6 & 7 \\
\hline Knowledge Dimension & $\square$ & $\square$ & $\square$ & $\square$ & $\square$ & $\square$ & $\square$ \\
\hline User interface of Go4C & $\square$ & $\square$ & $\square$ & $\square$ & $\square$ & $\square$ & $\square$ \\
\hline Five Interaction Phases & $\square$ & $\square$ & $\square$ & $\square$ & $\square$ & $\square$ & $\square$ \\
\hline CxO roles of the management board & $\square$ & $\square$ & $\square$ & $\square$ & $\square$ & $\square$ & $\square$ \\
\hline Calculation of interest rates & & $\square$ & $\square$ & $\square$ & $\square$ & $\square$ & $\square$ \\
\hline Customer savings finance car loans & & & $\square$ & $\square$ & $\square$ & $\square$ & $\square$ \\
\hline MIS balance sheet & & & $\square$ & $\square$ & $\square$ & $\square$ & $\square$ \\
\hline MIS profit and loss statement & & & $\square$ & $\square$ & $\square$ & $\square$ & $\square$ \\
\hline MIS Balanced Scorecard & & & & $\square$ & $\square$ & $\square$ & $\square$ \\
\hline Human resources management & & & & & $\square$ & $\square$ & $\square$ \\
\hline Information management/ IT-infrastructure & & & & $\square$ & $\square$ & $\square$ & $\square$ \\
\hline MIS project management & & & & & & $\square$ & $\square$ \\
\hline Business objectives and indicators & & & $\square$ \\
\hline
\end{tabular}

With questions like: "What does a car financing bank actually do?", "Which tasks do I have to perform to manage this business?" the tutors lead the participants towards deciding on sound business objectives for TechniCar at the start of the second iteration: e.g. profit leader, cost leader, market leader. They should develop a reasonable strategy based on the principle: "customer savings finance car loans". This strategy should be consistently implemented and - if necessary - further improved during the following iterations.

Go4C comprises a total of about a thousand different financial and non-financial indicators that are linked with each other by means of System Dynamics [1].

Participants must follow up on these indicators during the iterations. But you can't keep track of a thousand indicators at a time. You have to focus on the key indicators. Therefore it is important that the participants gradually learn to keep record of the progress of those indicators that are relevant according to their individual business objective and strategy.

Each iteration ends with the fifth Interaction Phase 'present the results'. Here the tutors - playing the part of the supervisory board - guide the management boards to: 
- Realign discrepant actual results to the targeted business objective and learn from the knowledge gained [14]

- Integrate a new task into their business strategy, i.e. one of those tasks that are related to the next knowledge dimension according to Table II.

According to our experience, you should choose the MIS balance sheet, profit and loss statement and the Balanced Scorecard as the central themes to discuss from the third iteration on. Beginning with the fourth iteration, the knowledge dimensions human resources management and information management/ IT infrastructure should be addressed. From the fifth iteration on, the project management feature of Go4C optimizes the performance of the business processes of TechniCar, thereby increasing the net income significantly.

Is net income the very best objective of entrepreneurship? Are there additional business objectives, which describe business excellence even better? Which business indicators support those objectives? These questions should be explored beginning with the sixth iteration. Having finished the seventh iteration we continue with the stage Conclusion.

\section{E. Conclusion}

The stage Conclusion of our didactic framework returns again to the scenario 'Paper Snippets'. Each management board summarizes their business objectives, strategies and the key measures that account for the company's success. The teams reflect on the knowledge dimensions and both their successful and not successful decisions. Each statement should be justified by the proper indicators of the MIS, following the structure established by the balance sheet, profit and loss statement and the Balanced Scorecard.

The entire final presentation is staged as an executive summary addressed to the supervisory board. The supervisory board assesses the executive summaries according to selected indicators (see Table III). A ranking of the teams is drawn up. The most expedient approaches will be honored. The most successful management board will be celebrated - in this case team D.

TABLE III. RANKING

\begin{tabular}{|l|c|c|c|c|c|}
\hline Indicator Team & A & B & C & D & E \\
\hline Net income & 3 & 2 & 4 & 1 & 5 \\
\hline Customer quality & 2 & 1 & 5 & 3 & 4 \\
\hline Processing time & 1 & 3 & 4 & 2 & 5 \\
\hline Market share & 4 & 2 & 3 & 1 & 5 \\
\hline Number of employees & 2 & 3 & 5 & 1 & 4 \\
\hline Ranking & III & II & IV & I & V \\
\hline
\end{tabular}

In the introductory scenario 'Paper Snippets' (see chapter V.C), the chairman of the supervisory board invited the future top managers to consolidate TechniCar first and then to ensure its sustained economic success. Typically, good teams master the consolidation by the third iteration. After the fifth iteration, all teams succeed in increasing the net income from an initial loss of 26 million U.S. dollars to a profit of up to 75 million U.S. dollars per half-year.

As integral part of the executive summaries, we encourage each participant to reflect - in addition to the business related aspects - on his key learnings related to the study skills. In the remaining part of this paper we focus on this issue.

\section{F. The Study Skills and the Didactic Framework}

Now we should be ready to answer the central question of this paper: How do the study skills correspond with the Didactic Framework of Go4C?

Table IV shows how the Interaction Phases and their iterations are related to the methods of science. The pie charts show to what extent a phase helps to acquire one of the five sub-aspects. The more the pie is shaded the stronger a phase is connected to a single sub-aspect.

By choosing this kind of visualization we refer to the representation of the learning objectives according to Bloom, Krathwohl and Anderson [20]. Thus Table IV illustrates the very heart of the curriculum of the Pupils' Academy.

TABLE IV. STUDY SKILLS AND DIDACTIC FRAMEWORK

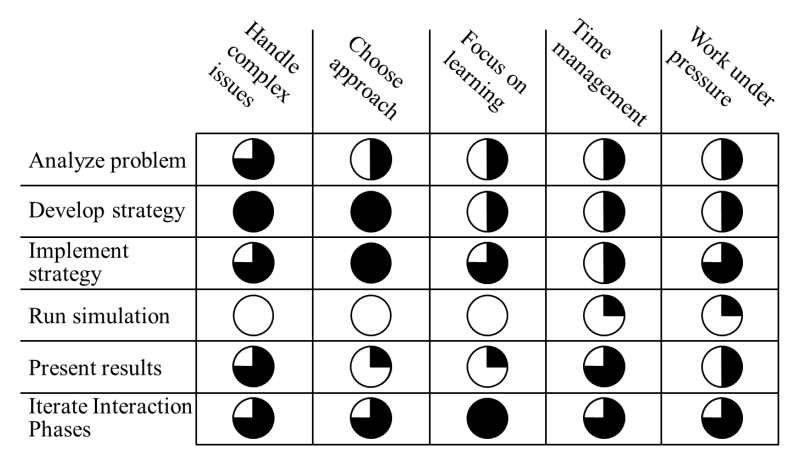

The following chapter describes the results of learning according to that curriculum.

\section{The Results of The PuPILs' AcAdemY}

How well does the Pupils' Academy of Serious Gaming strengthen their study skills? We invited the participants to help us answer this question.

We reviewed the effectiveness of the Pupils' Academy with a computer based questionnaire. All participants rated their own study skills before and after attending the Pupils' Academy. We visualized the results of this rating by comparing both estimates for each of the (sub-) aspects of the study skills as presented in chapter three.

For the IT-based questionnaire, the various aspects of the study skills were converted into first-person statements. The rating of each statement is based on a Likert scale, which comprises five (dis)agreement levels (see Fig. 3). The participants needed about 15 minutes for carefully processing the entire questionnaire.

We interpreted the results of the survey together with the participants at a work-shop held one week after the Pupils' Academy.

We were particularly interested in specific proposals on the improvement of the Pupils'

\begin{tabular}{|c|}
\hline Strongly agree \\
\hline Agree \\
\hline Neither agree nor disagree \\
\hline Disagree \\
\hline Strongly disagree \\
\hline
\end{tabular}

Figure 3. Likert scale Academy.

In the following we visualize the summarized ratings. 


\section{A. Results on methods of science}

The students formulated the most important condition for acquiring methods of science (see Fig. 4) as follows: "The complexity of the business game was so overwhelming that we didn't understand anything during the first turn", but then "... from the third turn on we got the knack!"

The turn-based nature of the game motivates the participants not only to recognize but to admit and correct their own mistakes. This leads to continuous improvement. The data basis for this improvement is the MIS of Go4C as described in chapter four. During the first two iterations, the students experience the MIS as an unfamiliar, complex system. The more they deal with the MIS in the following iterations, the more they treasure it as an "essential and indispensable aid".

The participants especially value the MIS feature of comparing the results both among all management teams and with the Go4C-Benchmark of the tutors. "I was given the choice to select out of a couple of strategies, the one serving my business goals best."

A student summarizes his overall judgment: "I had to work in a concentrated way and under pressure for two days. Nevertheless, I had a lot of fun." With the 5th turn each team managed to lead TechniCar towards success.

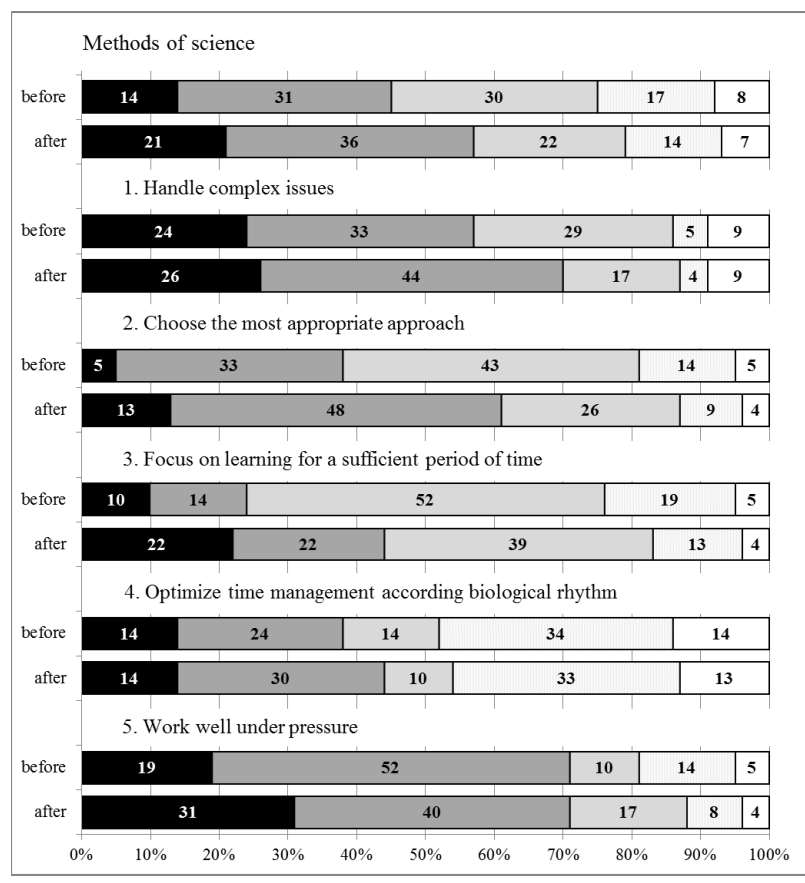

Figure 4. Rating results on methods of science

"Wow - we just raised the bar: our net income grew up to 75 million U.S. dollars" a participant rejoiced after the last turn.

\section{B. Results on a clear idea of the studies at university}

The Pupils' Academy prompts the students of the upper vocational schools to get a clear idea of the studies at university (see Fig. 5). They tell us: "Before the Academy, I thought: 'I know everything that is important about studying'. Afterwards, I see far more clearly what studying really means."

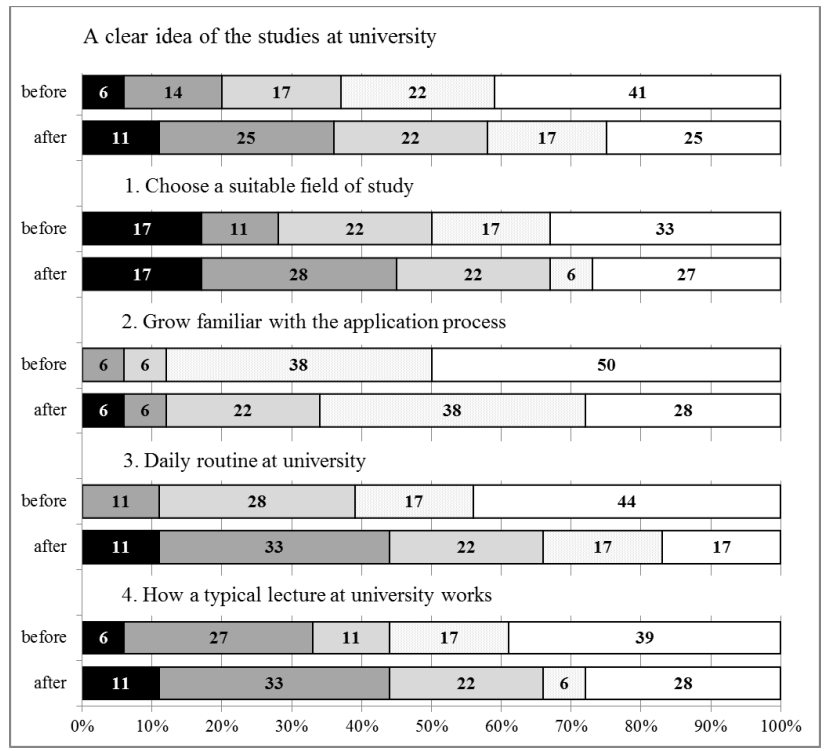

Figure 5. Rating results on a clear idea of the studies at university

Our key finding of the Pupils' Academy is: the $11^{\text {th }}$ graders of upper vocational schools BOS and FOS do not have a very clear idea of their future after school.

The unanimous opinion is: "First thing I have to do is to obtain the university entrance certification. Afterwards I'll deal with all the organizational details of an application at university." That is precisely the starting-point of the Pupils' Academy. The $11^{\text {th }}$ graders "live" at university for two days under real conditions of studying - one year before they actually graduate. This inspires them to strive for a clear idea of the studies at university.

\section{Comparison of the 'Abitur' results}

The questionnaire on the study skills gave us valuable hints for improving the Pupils' Academy. In addition, it leads the $11^{\text {th }}$ graders to deal with the (sub-) aspects of the study skills in depth. Nevertheless, the questionnaire, like any evaluation depending on the participants' selfassessment, offers - from a scientific point of view - very little information about what the $11^{\text {th }}$ graders gained.

Which other indicators are suitable to evaluate the success of the Pupils' Academy? In response to this question, in the year 2013, we explored another indicator: the results of the final exam, the German 'Abitur' (Fig. 6).

In 2014, the former $11^{\text {th }}$ graders who had participated in the Pupils' Academy in 2013 were in grade 12 that ends with the 'Abitur'. Thus we can use all 401 'FOS/ BOS Munich for Technology' graduates of the school year 2014 as a control group for a comparison (

What about comparing the 'Abitur' of the Pupils' Academy participants with the control group's 'Abitur' as an indicator of the success of the Pupils' Academy?

As a basis for this we invited two different groups of $11^{\text {th }}$ graders to the Pupils' Academy of 2013:

group I: an entire class whose grade records are representative of grade 11 students

group-II: students who are proposed by a teachers' department meeting. 
Fig. 6 compares the 2014 'Abitur' results of group-I and group-II with the control group on a scale of 1 to 4 ( 1 =excellent, $2=$ good, $3=$ satisfactory, $4=$ pass mark/ sufficient). This comparison suggests that the 'Abitur' grades of the Pupils' Academy participants show an improved average of 2.65 compared with an average of 3.05 for the control group. The participants of the Pupils' Academy achieve a lower failure rate of $0.09 \%$ compared to $16.21 \%$ in the control group.

Based on the results of this comparison, we decided to keep on collecting and analyzing the 'Abitur' results for each participant of the Pupils' Academy in addition to the questionnaire on the study skills.

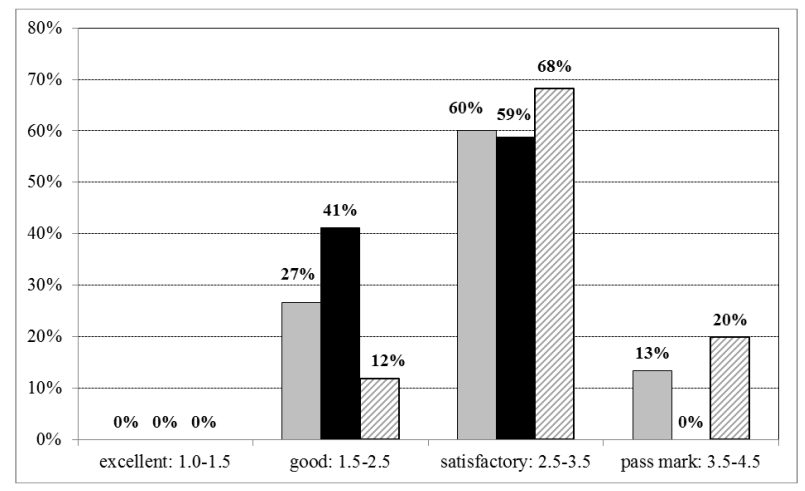

Figure 6. Abitur Result Comparison 2014

\section{CONCLUSION}

For five years now we have been inviting highly talented students of the $11^{\text {th }}$ grade of the upper vocational schools BOS and FOS in Bavaria to the Pupils' Academy of Serious Gaming at TUM. Did we achieve the ambitious goal of strengthening the students' study skills at the gateway between university and upper vocational school?

Improving the study skills requires the students to change their learning behavior. The Pupils' Academy takes two days. On the one hand, that is nowhere near enough for learning to master all aspects of the study skills. But on the other hand, it definitely is sufficient time to raise the students' awareness and to provide detailed information on particularly important aspects of the study skills, like the five methods of science. "I've learned to evaluate my study skills", one student said.

In addition to their everyday life at school, the students of the upper vocational schools experience technical content and learning methods from the perspective of a university. They master the first steps towards adjusting their learning behavior to university needs with professional assistance. They experience the first successful behavioral changes thus increasing their self-confidence. Each student is given a fresh impetus to further enhance their study skills autonomously. The students phrase it this way: "In future I'll be striving for an excellent graduation because now I know why", "I am able to enhance my study skills" and "I've experienced: Learning is fun!"

\section{ACKNOWLEDGMENT}

The author would like to thank Mrs. Gudrun Innertsberger for supporting the analysis of data and $\mathrm{Mr}$. Andreas Sirch, and Mrs. Rebekka Utesch for their contri- bution to reviewing the article. Finally let me express special thanks to Professor Dr. Helmut A.O. Krcmar and his institute at TUM: with your help, the Pupils' Academy became reality!

\section{REFERENCES}

[1] H. Krcmar und M. Utesch, Planen und Entscheiden: Das Planspiel Go4C, München: Books on Demand, 2011.

[2] B. Staatsministerium, ,Schule und Bildung in Bayern: Statistische Übersichten," München, 2014.

[3] ISB, Beruf und Studium - BuS, München: Kastner AG - das medienhaus, 2005.

[4] E. Klopfer, Augmented Learning: Research and Design of Mobile Educational Games, Education next, 2008. http://dx.doi.org/10.7551/mitpress/9780262113151.001.0001

[5] J. Piaget, „Problems of Equilibration,“ In Appel, M. $H$ and Goldberg, L. S. (1977). Topics in Cognitive Development, Volume 1: Equilibration: Theory, Research and Application, Plenum Press, NY, pp. 3-13, 1977.

[6] M. Utesch, D. Bösl, P. Boscolo und C. Helfer, „Erfahrungsbericht zu Serious Gaming - C\# Entwicklung mit AntMe!,“ Embedded Software Engineering Kongress ESE, pp. 611-616, 2009.

[7] B. J. Zimmermann, „Self-Egulated Learning and Academic Achievement: An Overview,“ Educational Psychologist, Nr. 25(1), pp. 3-17, 1990. http://dx.doi.org/10.1207/ s15326985ep2501 2

[8] OECD, „Schooling for Tomorrow - Personalising Education,“ OECD Publishing, Paris, 2006.

[9] R. S. Kaplan und D. P. Norton, Balanced Scorecard: Translating Strategy into Action, Boston: Harvard Business School Press, 1996.

[10] O. Graven und L. M. MacKinnon, „Exploitation of games and virtual environments for elearning, " in Ultimo: ITHET7th International Conference on Information Technology Based Higher Education, 2006.

[11] W. McKeachie und M. Svinicki, McKeachie's Teaching Tips, Belmont: Wadsworth, 2013.

[12] P. Pivec, „Game-based Learning or Game-Based Teaching,“ in Becta, 2009.

[13] R. Garris, R. Ahlers und J. E. Driskell, „Games, Motivation, and Learning: a Research and Practice Model,“ Simulation \& Gaming, pp. 441-467, December 2002. http://dx.doi.org/10.1177/1046 $\underline{878102238607}$

[14] N. Keith und M. Frese, „Effectiveness of error management training: A meta-analysis,“ Journal of Applied Psychology, p. 93, 2008. http://dx.doi.org/10.1037/0021-9010.93.1.59

[15] A. Aviram, Navigating Through the Storm: Reinventing Education for Postmodern Democracies, Rotterdam: Sense Publishers, 2010.

[16] U. Welbers, The Shift from Teaching to Learning, Bielefeld: W. Bertelsmann Verlag, 2005.

[17] E. Aronson und P. Shelley, Cooperation in the Classroom, The Jigsaw Method, London: Addison-Wesley, 2011.

[18] M. Csíkszentmihályi, Flow: the Psychology of Happiness, London: Random House, 1992.

[19] N. Peirce, O. Conlan und V. Wade, „Adaptive Educational Games: Providing Non-invasive Personalised Learning Experiences," in Second IEEE International Conference on Digital Game and Intelligent Toy Enhanced Learning, Banff, 2008. http://dx.doi.org/10.1109/DIGITEL.2008.30

[20] L. Anderson und D. Krathwohl, A Taxonomy for Learning, Teaching, and Assessing. A Revision of Bloom's Taxonomy of Educational Objectives, New York: Addison Wesley Longman, 2001. 
[21] A. Böttcher und M. C. Utesch, „Software Engineering: Zeitgemäße Lern- und Lehrstrategien. Pair Teaching und Bloom'sche Taxonomie," in Embedded Software Engineering Kongress, Sindelfingen, 2009.

\section{AUTHOR}

M. C. Utesch is with the upper vocational school 'Staatliche Fachober- und Berufsoberschule Technik', Bergsonstraße 109, 81245 Munich and the 'Technische Universität München', Faculty of Informatics, institute for Information Systems, Boltzmannstr. 3, 85748 Garching, Germany (e-mail: utesch@in.tum.de). He was a member of the Core Advisory Board of the EU Sixth Framework Programme/ iclass. His main interests include IT-based learning, games engineering and in particular the enhancement of the study skills at the interface between school and university.

This article is an extended and modified version of a paper presented at the EDUCON2015 conference held at Tallinn University of Technology, Tallinn, Estonia, 18-20 March 2015. Submitted, 25 April 2015. Published as resubmitted by the authors 25 June 2015. Submitted 26 April 2015. Published as resubmitted by the author 25 June 2015. 